\title{
Adrenal incidentaloma. Current situation in Lithuania
}

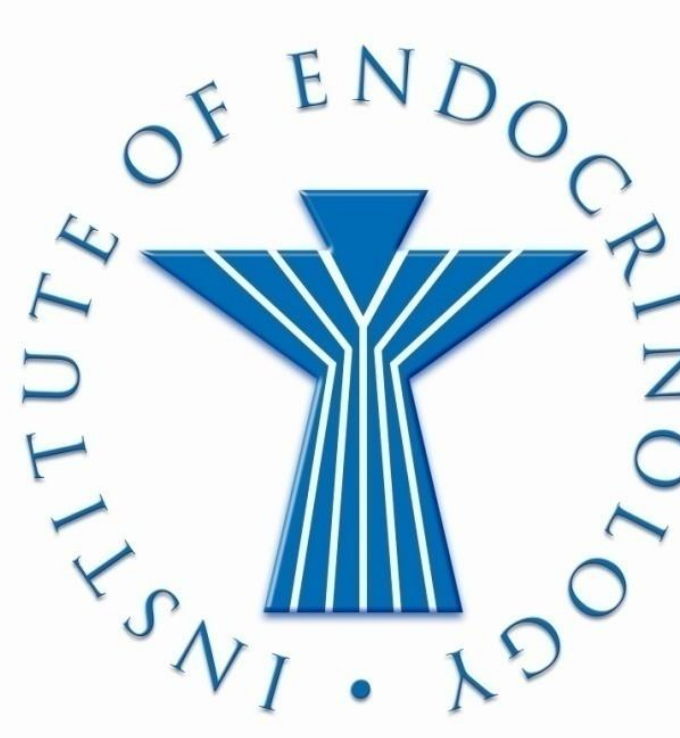

Ilona Banišauskaitė, Valentinas Matulevičius, Rytas Ostrauskas, Lina Barsienė, Rasa Verkauskienė, Žydrūnè Visockiené*, Justina Jurevičiūtè, Indrè Matulevičiūtè.

Lithuanian University of Health Sciences

Vilnius University*

\section{Introduction.}

Adrenal incidentaloma is an adrenal tumor incidentally discovered in the region of adrenals, usually investigating for non endocrine disease. Most of these compounds are benign adrenal adenomas. We attempted to find out the current situation of adrenal incidentaloma in Lithuania.

\section{Results \\ Referral diagnosis}

$\square 2007 \square 2011$

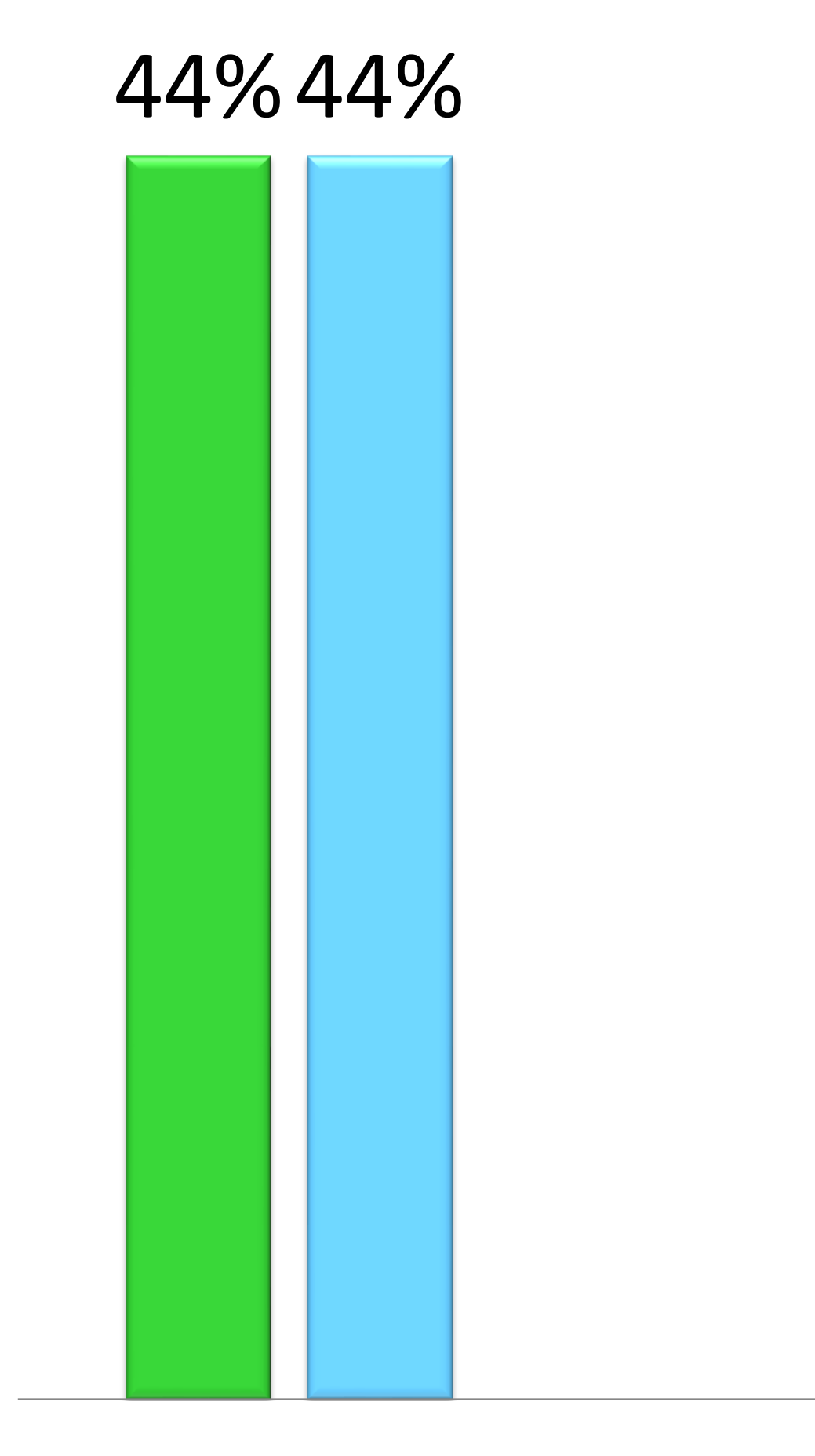

Pheochromocytoma

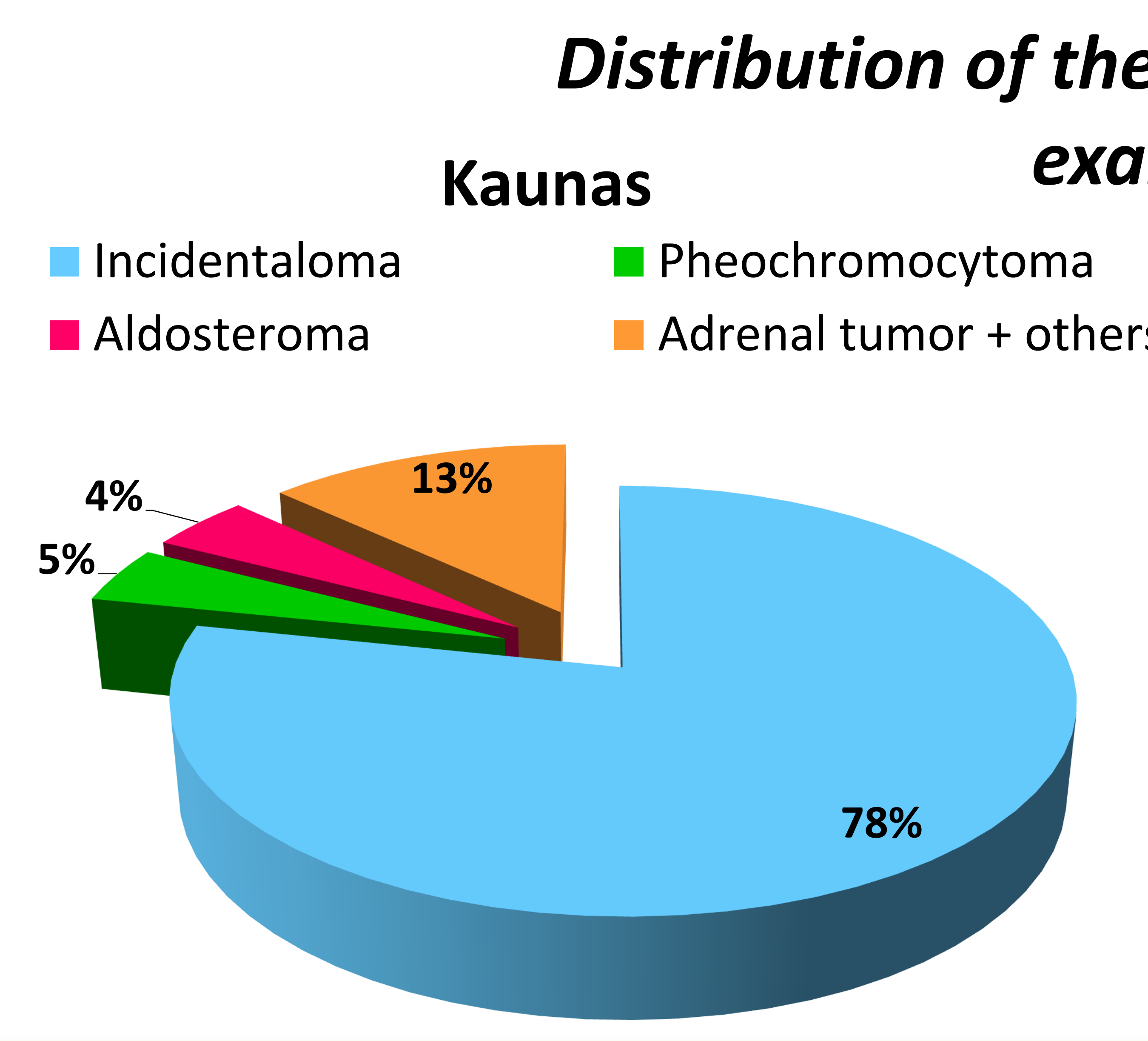

\section{Conclusions.}

1. From 2007 to 2011 cases of adrenal tumors increased twice.

2. In Lithuania incidence of adrenal incidentaloma depends on the availability of visual research methods.

3. The retrospective study has some defects, one of them is lack of information, so prospective study of adrenal incidentaloma at the national level is discussed.

Number of patients with adrenal tumor in 2007 and 2011 in Lithuania

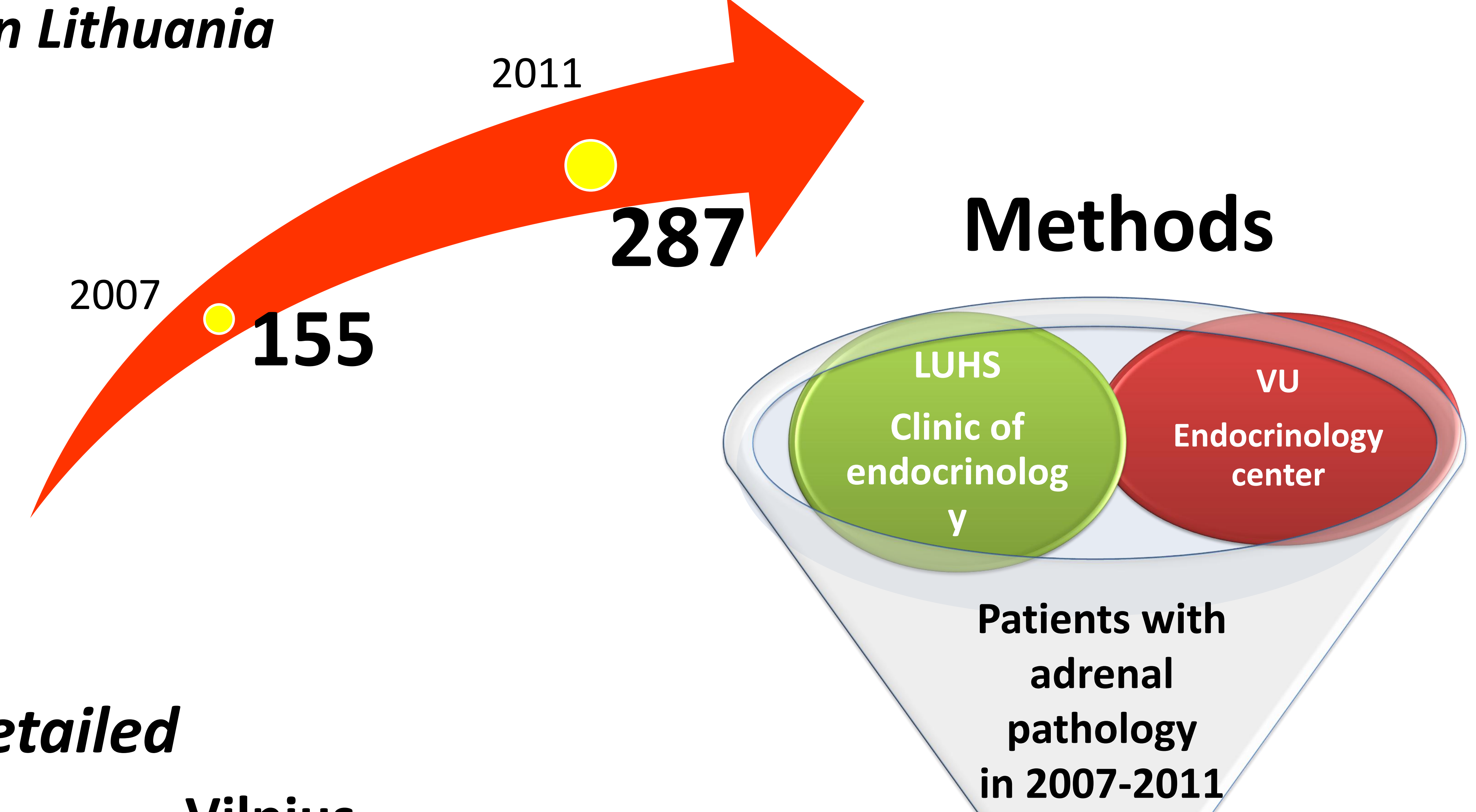

Vilnius

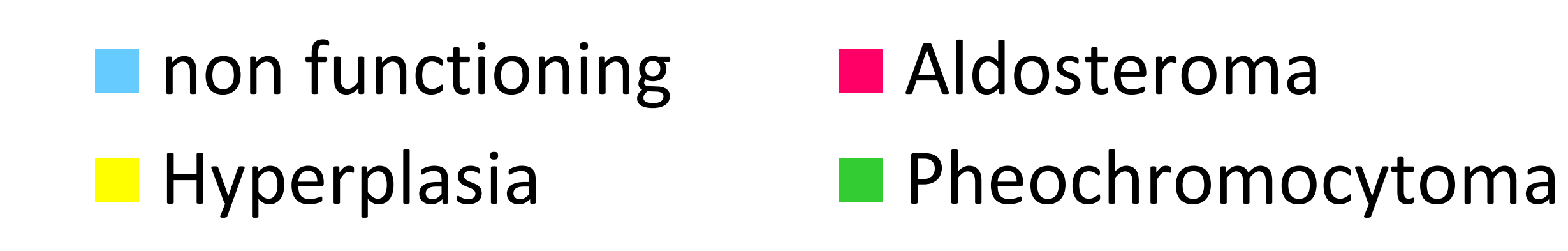

Found

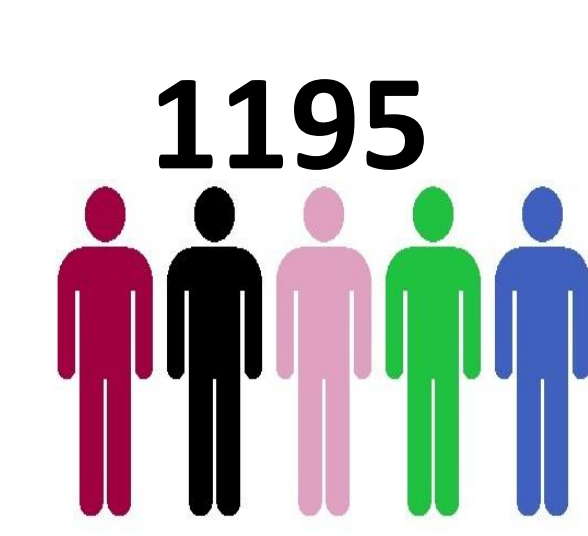

Analysed

104

iil

\section{Future plans: The prospective study of adrenal incidentaloma in Lithuania}

The aim:

To evaluate the prevalence and characteristics of incidentaloma in Lithuania.

Objectives:

- To evaluate the prevalence of incidentaloma in Lithuania

- To determine the dependence by age and gender, to assess the hormonal activity, the size of the tumor and to identify the most common complaints.

1. Aron D, Terzolo M, Cawood TJ. Adrenal incidentaliomas. Best Pract Res Clin Endocrinol Metab 2012;26(1):69-82.

2. Anagnostis P, Karagiannis A, Tziomalos K, Kakafika Al, Athyros VG, Mikhailidis DP. Adrenal incidentaloma: a diagnostic challenge. Hormones (Athens). 2009 Jul-Sep; 8 (3): 163-84.

3. Oh JY. How to approach and follow adrenal incidentaloma? Korean J Intern Med. 2013 Sep; 28 (5): 541-3. 